\title{
Establishment of Quick Testing Efficiency Evaluation Model and Analysis of Related Factors
}

\author{
Dan Li \\ Nanjing Institute for Food and Drug Control, Nanjing, China \\ Email: lidan_ing@126.com
}

How to cite this paper: Li, D. (2016) Establishment of Quick Testing Efficiency Evaluation Model and Analysis of Related Factors. Food and Nutrition Sciences, 7, 1232-1240. http://dx.doi.org/10.4236/fns.2016.713113

Received: September 17, 2016

Accepted: November 1, 2016

Published: November 4, 2016

Copyright $\odot 2016$ by author and Scientific Research Publishing Inc. This work is licensed under the Creative Commons Attribution International License (CC BY 4.0).

http://creativecommons.org/licenses/by/4.0/

(c) (i) Open Access

\begin{abstract}
Objective: "Rapid screening, targeted sampling, objective test" is an efficient test model. The factors affecting the efficiency include false screening rate, missing rate and rapid screening time. However, only missing rate and accuracy have been used as technical requirements to evaluate rapid screening method. In this study, efficiency was regarded as evaluation index of quick testing method. Method: The evaluation model of quick testing efficiency was established by comparing time of routine testing and quick testing. By simulation calculation, the effect factors such as rapid screening time, false screening rate, missing rate and defective rate were analyzed. Results: The calculation formula of efficiency was derived. Simulation results showed that the lower defective rate, the higher efficiency; the smaller missing rate, false screening rate, or screening time, the higher efficiency and the degree of improving efficiency is related to defective rate; sometimes, the screening time is the most important factor affecting the efficiency. In certain cases, if the false screening rate or missing rate is $50 \%$, the efficiency can be increased by more than 10 times. Conclusions: Taken together, this study highlighted a role of efficiency which functioned as an index to evaluate rapid screening. Quick testing efficiency evaluation model can be used for the calculation efficiency, and can be used to analysis the relationship between efficiency and the influence factors, and can provide the theoretical foundation for rapid screening method development and evaluation.
\end{abstract}

\section{Keywords}

Efficiency Evaluation, Rapid Screening Time, Missing Rate, False Screening Rate

\section{Introduction}

Food and drug market circulation is huge but regulatory supervision is limited. WHO put forward the concept of fighting against "substandard/spurious/falsely-labelled/falsi- 
zhfied/counterfeit medical products (SSFFCs)". "Rapid screening, targeted sampling, objective test" is an efficient test pattern [1] [2]. For example, in 2010, food and drug administration carried out special supervision and sampling inspection for health food that was added illegal chemicals. Rapid screening 3000 batches of samples and 165 batches of them turned out to be positive. But through objective test, there are 98 batches of sample proved positive. It took only two weeks. Compared to test 3000 batches and many projects, efficiency is improved obviously [3].

Rapid screening methods have been widely applied to food [4] [5], medicines [6] [7], health food [8] [9] and similar health products. But the food and drug safety situation is still not optimistic [10] [11] and rapid screening methods need further research and development.

Opinions about technical requirements vary from person to person. Guide for determination of health food and cosmetics rapid screening method printed by China Food and Drug Administration in 2012 [12] set that the false positives rate should be less than $20 \%$ and the correct screening rate should be more than $80 \%$. Theories and Practices of Rapid Screening Technologies for Adulteration in Health Products written by Xie Zhijie suggested that the false positives rate should be less than $10 \%$; missing rate should be less than 5\%; and the correct screening rate should be more than $90 \%$ [3]. However, some simple methods can be used for screening to improve efficiency evidently, but do not fit technical requirements. For example, if correct screening rate is $60 \%$ (false screening rate is $40 \%$ ) [3], efficiency is improved clearly. This study considers that improving the test efficiency is the purpose of rapid screening. Correct screening rate is just one factor that affects the efficiency because positive samples need to be confirmed.

Comparing with routine testing time and quick testing time, an evaluation model to calculate quick testing efficiency is established considering the impact of rapid screening time, false screening rate, missing rate and defective rate. By simulation calculation, the relationship between efficiency and affect factors is analyzed.

\section{Method}

In this paper, without calculating the economic cost of testing, we only consider the time to study technical efficiency. Comparing time of routine testing and quick testing, various factors that effect efficiency are analyzed by simulation calculation

\subsection{Concept Definition}

1) Rapid screening: It means a kind of rapid test for specific project to sample. The result could be true, but sometimes it could also be false positive or false negative.

2) Objective test: This method is to confirm the positive result of rapid screening through a testing method in law.

3) Quick testing: It means an efficient testing pattern combining rapid screening and objective test. This pattern could be used to determine the positive samples quickly and accurately.

4) Number of unqualified products checked out is represented by $P$. 
5) False positives number is represented by $F_{P}$.

6) False negative number is represented by $L_{P}$.

7) Routine test time for all items in the lab is represented by $t_{1}$.

8) Rapid screening time is represented by $t_{2}$.

9) Objective testing time for positive sample is represented by $t_{3}$.

10)Defective rate is represented by $a \%$.

11)False screening rate: false positive expressed as a percentage of screening positive

$$
\frac{F_{P}}{P+F_{P}} \times 100 \%
$$

12)Missing rate: false negative expressed as a percentage of true positive

$$
\frac{L_{P}}{P+L_{P}} \times 100 \%
$$

13)Efficiency value is represented by $E$.

14)Efficiency difference with sing-factor changed is represented by $D$-value.

\subsection{Establish Efficiency Evaluation Model of Quick Testing}

When product quantity is equal, work efficiency and time is inversely ratio. Efficiency can be calculated by the ratio of routine testing time to quick testing time.

1) Quick testing time is the sum of rapid screening and laboratory verification time. False positive and false negative affect quick testing efficiency. When the same unqualified number of products is checked out, the relationship between testing time and unqualified number is in Table 1.

2) Formula derivation of efficiency

$$
\begin{aligned}
& E=\frac{\frac{P}{a \%} \times t_{1}}{\frac{P+L_{\mathrm{P}}}{a \%} \times t_{2}+\left(P+F_{\mathrm{P}}\right) \times t_{3}} \\
& =\frac{P \times t_{1}}{P \times t_{2}+L_{P} \times t_{2}+\left(P+F_{P}\right) \times t_{3} \times a \%} \\
& =\frac{t_{1}}{t_{2}+\frac{L_{P}}{P} \times t_{2}+t_{3} \times a \%+\frac{F_{P}}{P} \times t_{3} \times a \%}
\end{aligned}
$$

Table 1. The relationship between testing time and unqualified number.

\begin{tabular}{cccc}
\hline Test type & Number of sample & Test time & Total test time \\
\hline Routine testing & $\frac{P}{a \%}$ & $t_{1}$ & $\frac{P}{a \%} \times t_{1}$ \\
Rapid screening & $\frac{P+L_{\mathrm{p}}}{a \%}$ & $t_{2}$ & $\frac{P+L_{\mathrm{p}}}{a \%} \times t_{2}$ \\
Objective testing & $P+F_{P}$ & $t_{3}$ & $\left(P+F_{P}\right) \times t_{3}$ \\
\hline
\end{tabular}




\subsection{Simulation}

First step: A quick testing method efficiency is simulated by formula (3) under the condition of missing rate is $50 \%$, false screening rate is $50 \%$, screening time is $0.25 \mathrm{~h}$ with defective rate is $1 \% \sim 50 \%$. Second step: Three quick testing methods efficiency are simulated by single-factor changed. Third step: The effect of each factor on efficiency is analyzed by calculating efficiency D-value. Fourth step: Three factors are evaluated synthetically by comparing analysis.

1) Simulation of a quick testing method

$t_{1}=10 \mathrm{~h}, t_{2}=0.25 \mathrm{~h}, t_{3}=2 \mathrm{~h} ; L_{\mathrm{P}} / p=1$ (missing rate is $50 \%$ ); $F_{\mathrm{p}} / p=1$ (false screening rate is $50 \%$ ), see Table 2 .

2) Simulation of single-factor changes

$t_{1}=10 \mathrm{~h}, t_{2}=0.25 \mathrm{~h}, t_{3}=2 \mathrm{~h} ; L_{\mathrm{P}} / p=0.25$ (missing rate is $20 \%$ ); $F_{\mathrm{p}} / p=1$ (false screening rate is $50 \%$ ), see Table 3 .

$\mathrm{t}_{1}=10 \mathrm{~h}, \mathrm{t}_{2}=0.25 \mathrm{~h}, \mathrm{t}_{3}=2 \mathrm{~h} ; L_{\mathrm{P}} / p=1$ (missing rate is $50 \%$ ); $F_{\mathrm{p}} / p=0.25$ (false screening rate is $20 \%$ ), see Table 4 .

$t_{1}=10 \mathrm{~h}, t_{2}=0.1 \mathrm{~h}, t_{3}=2 \mathrm{~h} ; L_{\mathrm{P}} / p=1$ (missing rate is $50 \%$ ); $F_{\mathrm{p}} / p=1$ (false screening rate is $50 \%$ ), see Table 5 .

3) Analysis of each single-factor

D-value with different missing rate, see Table 6.

D-value with different false screening rate, see Table 7.

D-value with different screening time, see Table 8.

Table 2. Efficiency evaluation forms (missing rate is $50 \%$; false screening rate is $50 \% ; t_{1}=10 \mathrm{~h} ; t_{2}$ $\left.=0.25 \mathrm{~h} ; t_{3}=2 \mathrm{~h}\right)$.

\begin{tabular}{ccccc}
\hline $\mathrm{a} \%$ & $L_{\mathrm{P}} / P$ & $F_{\mathrm{P}} / P$ & $t_{2}$ & $\mathrm{E}$ \\
\hline $1 \%$ & 1 & 1 & 0.25 & 18.52 \\
$10 \%$ & 1 & 1 & 0.25 & 11.11 \\
$20 \%$ & 1 & 1 & 0.25 & 7.69 \\
$30 \%$ & 1 & 1 & 0.25 & 5.88 \\
$40 \%$ & 1 & 1 & 0.25 & 4.76 \\
$50 \%$ & 1 & 1 & 0.25 & 4.00 \\
\hline
\end{tabular}

Table 3. Efficiency evaluation forms (missing rate is reduced).

\begin{tabular}{ccccc}
\hline $\mathrm{a} \%$ & $L_{\mathrm{P}} / P$ & $F_{\mathrm{P}} / P$ & $t_{2}$ & $\mathrm{E}$ \\
\hline $1 \%$ & 0.25 & 1 & 0.25 & 28.37 \\
$10 \%$ & 0.25 & 1 & 0.25 & 14.04 \\
$20 \%$ & 0.25 & 1 & 0.25 & 8.99 \\
$30 \%$ & 0.25 & 1 & 0.25 & 6.61 \\
$40 \%$ & 0.25 & 1 & 0.25 & 5.23 \\
$50 \%$ & 0.25 & 1 & 0.25 & 4.32 \\
\hline
\end{tabular}


Table 4. Efficiency evaluation forms (false testing rate is reduced).

\begin{tabular}{ccccc}
\hline $\mathrm{a} \%$ & $L_{\mathrm{P}} / P$ & $F_{\mathrm{P}} / P$ & $t_{2}$ & $\mathrm{E}$ \\
\hline $1 \%$ & 1 & 0.25 & 0.25 & 19.05 \\
$10 \%$ & 1 & 0.25 & 0.25 & 13.33 \\
$20 \%$ & 1 & 0.25 & 0.25 & 10.00 \\
$30 \%$ & 1 & 0.25 & 0.25 & 8.00 \\
$40 \%$ & 1 & 0.25 & 0.25 & 6.67 \\
$50 \%$ & 1 & 0.25 & 0.25 & 5.71 \\
\hline
\end{tabular}

Table 5. Efficiency evaluation form (screening time is reduced).

\begin{tabular}{ccccc}
\hline $\mathrm{a} \%$ & $L_{\mathrm{p}} / P$ & $F_{\mathrm{P}} / P$ & $t_{2}$ & $\mathrm{E}$ \\
\hline $1 \%$ & 1 & 1 & 0.1 & 41.67 \\
$10 \%$ & 1 & 1 & 0.1 & 16.67 \\
$20 \%$ & 1 & 1 & 0.1 & 10.00 \\
$30 \%$ & 1 & 1 & 0.1 & 7.14 \\
$40 \%$ & 1 & 1 & 0.1 & 5.56 \\
$50 \%$ & 1 & 1 & 0.1 & 4.55 \\
\hline
\end{tabular}

Table 6. The efficiency difference value when missing rate is reduced.

\begin{tabular}{ccccccc}
\hline & \multicolumn{7}{c}{$\mathrm{a} \%$} \\
\cline { 2 - 6 } & $1 \%$ & $10 \%$ & $20 \%$ & $30 \%$ & $40 \%$ & $50 \%$ \\
\hline $\mathrm{E}\left(L_{\mathrm{P}} / P=0.25\right)$ & 28.37 & 14.04 & 8.99 & 6.61 & 5.23 & 4.32 \\
$\mathrm{E}\left(L_{\mathrm{P}} / P=1\right)$ & 18.52 & 11.11 & 7.69 & 5.88 & 4.76 & 4.00 \\
$\mathrm{D}$-value & 9.85 & 2.93 & 1.30 & 0.73 & 0.47 & 0.32 \\
\hline
\end{tabular}

Table 7. The efficiency difference value when false testing rate is reduced.

\begin{tabular}{ccccccc}
\hline & \multicolumn{7}{c}{$\mathrm{a} \%$} \\
\cline { 2 - 6 } & $1 \%$ & $10 \%$ & $20 \%$ & $30 \%$ & $40 \%$ & $50 \%$ \\
\hline $\mathrm{E}\left(F_{\mathrm{P}} / P=0.25\right)$ & 19.05 & 13.33 & 10.00 & 8.00 & 6.67 & 5.71 \\
$\mathrm{E}\left(F_{\mathrm{P}} / P=1\right)$ & 18.52 & 11.11 & 7.69 & 5.88 & 4.76 & 4.00 \\
$\mathrm{D}$-value & 0.53 & 2.22 & 2.31 & 2.12 & 1.91 & 1.71 \\
\hline
\end{tabular}

Table 8. The efficiency difference value when screening time is reduced.

\begin{tabular}{ccccccc}
\hline & \multicolumn{7}{c}{$\mathrm{a} \%$} \\
\cline { 2 - 7 } & $1 \%$ & $10 \%$ & $20 \%$ & $30 \%$ & $40 \%$ & $50 \%$ \\
\hline $\mathrm{E}\left(t_{2}=0.1 \mathrm{~h}\right)$ & 41.67 & 16.67 & 10.00 & 7.14 & 5.56 & 4.55 \\
$\mathrm{E}\left(t_{2}=0.25 \mathrm{~h}\right)$ & 18.52 & 11.11 & 7.69 & 5.88 & 4.76 & 4.00 \\
D-value & 23.15 & 5.56 & 2.31 & 1.26 & 0.80 & 0.55 \\
\hline
\end{tabular}


4) Evaluation of the three effect factors

$\mathrm{D}$-value of missing rate, false screening rate and screening time are comparison analyzed. Three factors are evaluated synthetically, see Figure 1.

\section{Results and Analysis}

\subsection{Simulation Efficiency Value of a Quick Testing Method at Assumption Conditions}

If $t_{1}=10 \mathrm{~h} ; t_{2}=0.25 \mathrm{~h} ; t_{3}=2 \mathrm{~h}$, missing rate is $50 \%$ and false screening rate is $50 \%$. Results are shown as Table 2, efficiency value is from 18.52 to 4.00 with defective rate changes from $1 \%$ to $50 \%$; the smaller defective rate, the higher efficiency. The efficiency is 11.11 at defective rate is $10 \%$. It also means false screening rate or missing rate can be more than the technical requirements (20\%).

\subsection{Efficiency D-Value at Different Missing Rate Conditions}

Comparing Table 2 and Table 3, if false screening rate is 50\%, missing rate is $50 \%$ or $20 \%$, the lower missing rate, the higher efficiency of the quick testing. Efficiency Dvalue is from 9.85 to 0.32 with defective rate changes from $1 \%$ to $50 \%$, Efficiency $\mathrm{D}$-value shows that the smaller the defective rate, the more obvious effect of missing rate on the quick testing efficiency (see Table 6).

\subsection{Efficiency D-Value at Different False Screening Rate Conditions}

Comparing Table 2 and Table 4, if missing rate is $50 \%$, false screening rate is $50 \%$ or $20 \%$, the lower false screening rate, the higher efficiency of the quick testing. Efficiency $\mathrm{D}$-value is $0.53,2.22,2.31,2.12,1.91,1.71$ with defective rate from $1 \%$ to $50 \%$, efficiency $\mathrm{D}$-value shows that effects of false screening rate on efficiency is more obvious when the defective rate is $20 \%$ (see Table 7 ).

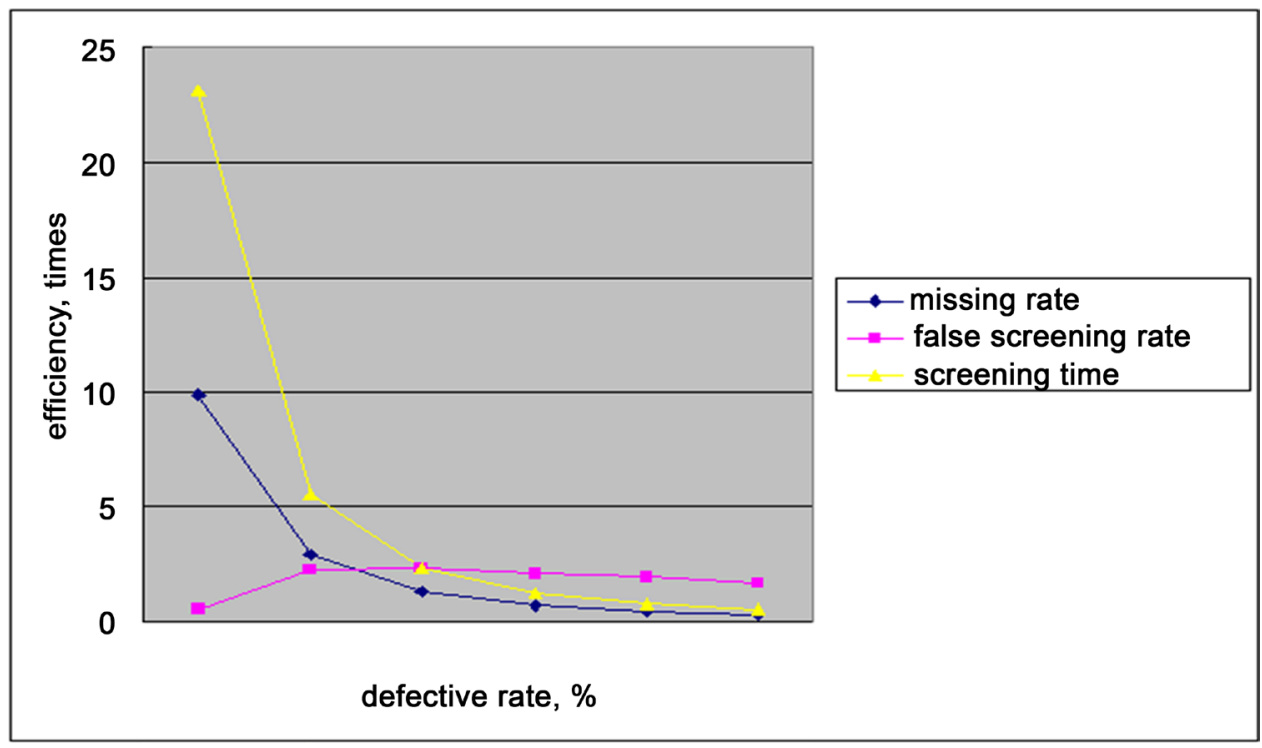

Figure 1. Comparative analysis evaluation form. 


\subsection{Efficiency D-value at Different Screening Time Conditions}

Comparing Table 2 and Table 5, if missing rate reduce is 50\%; false screening rate is $50 \%$, screening time is $0.25 \mathrm{~h}$ or $0.1 \mathrm{~h}$, the shorter screening time, the higher efficiency. Efficiency D-value is from 23.15 to 0.55 with defective rate changes from $1 \%$ to $50 \%$, results showed that the smaller the defective rate is, the more obvious effects of screening time on efficiency (see Table 8).

\subsection{Comparison Analysis of the Three Effect Factors}

Contrastive analysis of D-values in Tables 6-8, When defective rate $<20 \%$, screening time is the most obvious impact on efficiency and the second is missing rate, false screening rate is last; when defective rate $=20 \%$, the impact on the efficiency of screening time and false screening rate are equal and missing rate is last; when defective rate > $20 \%$, the impact on the efficiency of the false screening rate is greater than the screening time and missing rate is last (see Figure 1).

\section{Discussion}

Although rapid screening also called quick testing in many references, in this study, quick testing means an efficient testing pattern combining rapid screening and objective test. This pattern could be used to quickly and accurately determine the positive samples.

This paper analyzes the influence of the false screening rate, missing rate, screening time under the condition of different defective rate on efficiency value. By changing the single factor respectively. The degree of improving efficiency is analyzed. The efficiency of quick testing is related to defective rate. The degree of improving efficiency is related to defective rate, too. Therefore, the defective rate is not only as a basis for the topic, but also affects the technical requirements of screening methods, so it's necessary to use big data to analyse defective rate. Although unqualified samples exist in the market unevenly sometimes. No matter how much the efficiency value is, and it can be improved certainly. The lower defective rate, the higher efficiency. The higher defective rate, the more necessary sampling inspection. For example, if the defective rate is too high, more than $50 \%$, the efficiency of quick testing is too low and sampling inspection directly could be considered.

From an implementation standpoint, it is hard to reduce false testing rate and missing rate at the same time, reducing false testing rate usually means raising missing rate [3]. How to limit a reasonable range should take defective rate and the nature of the quick testing into consideration. For example, quick testing is applied to drug sampling inspection, sampling coverage should be increased, unqualified samples was found as far as possible; In terms of the Olympic food security, it is necessary to reduce the missing rate as far as possible; Access to agricultural products should be emphasized on the correct rate to reject unqualified samples and to ensure sales keep smoothly avoiding technical shortages. 


\section{Conclusions}

The primary objective of the study was to establish a method for evaluating a quick testing method. The secondary aim of the study was to find the relationship between quick testing efficiency and impact factors such as missing rate, false testing rate, screening time and defective rate.

The efficiency is regarded as an evaluation index of quick testing method. The formula of calculating efficiency was deduced by comparing time of routine testing and quick testing.

Relationship between efficiency and impact factors has been analyzed by simulation calculation. Factors are changed separately. The influence of each factor on efficiency is analyzed by efficiency value. The degree of each factor's influence on the efficiency has been analyzed by efficiency D-value. At last, Comparison Analysis of the degree of each factor's influence on the efficiency has been completed.

The results provided that the lower missing rate or false screening rate, the higher efficiency of the quick testing; the shorter screening time, the higher efficiency. Difference values mean that the degree of improving efficiency is related to defective rate. Sometimes, the screening time is the most important factor affecting the efficiency. In certain cases, if the false screening rate or missing rate is $50 \%$, the efficiency can be increased by more than 10 times.

The result of the study would enable policy and decision makers to pay more attention to efficiency; in addition, it would lead more rapid screening method to be developed. This would be one of the effective methods to ensure food and drug security.

The study can be used in food and drug; we can extend it to other fields such as disease diagnosis, environmental monitoring, etc.

\section{References}

[1] Shen, F., Chen, L., Lv, F.S., Zhu, Y.Z., Qian, Z.Y. and Liu, R. (2013) Discussion on Rapid Drug Detection. Shanghai Food and Drug Information Research, 8, 23-31.

[2] Zhang, M. and Lu, J. (2015) Discussion on Rapid Drug Detection in the Context of the 12th Five-Year Plan. Chinese Pharmaceutical Affairs, 6, 568-570.

[3] Xie, Z.J. (2011) Theories and Practices of Rapid Screening Technologies for Adulteration in Health Products. South China University of Technology Press, Guangzhou, 48-49, 90.

[4] Wang, H.J., Ma, F.M., Zhang, G.X. and Ji, W. (2013) The Study on Application of Fast Detection in Food Safety Regulation. Food Research and Development, 10, 118-121.

[5] Huang, Y.C., Ding, W.W., Zhang, Z.M. and Li, G.K. (2013) Development of Sample Pretreatment Techniques-Rapid Detection Coupling Methods for Food Security Analysis. Chinese Journal of Chromatography, 7, 613-619. http://dx.doi.org/10.3724/SP.J.1123.2013.04035

[6] Bian, Z.J., Li, Y.L., Jin, S.H., Li, B., Hu, C.Q. and Lu, J. (2013) Development and Application of Rapid Drug Detection Technology I. Chemical Medicines. Chemical Industry Press, Beijing.

[7] Bian, Z.J., Li, Y.L., Jin, S.H., Li, B., Hu, C.Q. and Lu, J. (2013) Development and Application of Rapid Drug Detection Technology II. Traditional Chinese Medicines. Chemical Industry 
Press, Beijing.

[8] Li, D., Wen, H.M., Cui, F.C., Huang, Y., Guo, C., Sun, X.R. and Yang, J.P. (2010) LCMS/MS Screening for 36 Chemical Components in Health Food and Chinese Traditional Patent Medicine. Chinese Journal of Pharmaceutical Analysis, 8, 1527-1532.

[9] Dong, P.Z., Guo, Z.X., Zhu, J., Wang, H. and Zhu, Z.F. (2016) On the Fast-Testing Method for Health Food Testing. Chinese Pharmaceutical Affairs, 1, 46-49.

[10] Wei, F., Liu, W., Yan, H., Shi, Y., Zhang, W.J., Zhang, P., Cheng, X.L. and Ma, S.C. (2015) National Wide Quality Surveillance and Analysis of Chinese Material Medical and Decoction Pieces. Chinese Pharmaceutical Journal, 4, 277-283.

[11] Zeng, C.P. and Xie, Y. (2016) Evaluation and Analysis on Quality of Traditional Chinese Herbal Pieces in Hebei Province. Chinese Pharmaceutical Affairs, 1, 41-45.

[12] http://www.sda.gov.cn/WS01/CL0847/73102 1.html

Submit or recommend next manuscript to SCIRP and we will provide best service for you:

Accepting pre-submission inquiries through Email, Facebook, LinkedIn, Twitter, etc. A wide selection of journals (inclusive of 9 subjects, more than 200 journals)

Providing 24-hour high-quality service

User-friendly online submission system

Fair and swift peer-review system

Efficient typesetting and proofreading procedure

Display of the result of downloads and visits, as well as the number of cited articles

Maximum dissemination of your research work

Submit your manuscript at: http://papersubmission.scirp.org/

Or contact fns@scirp.org 